\title{
OS LIMITES ENTRE A DEFESA DO DIREITO À VIDA E À MORTE: UMA ANÁLISE ATUAL DA EUTANÁSIA NO BRASIL
}

\author{
Suelen Agum dos Reis ${ }^{*}$ \\ Raquel Fonseca de Oliveira ${ }^{* *}$
}

\section{RESUMO:}

Este artigo tem por objetivo refletir a situação de pacientes terminais, com doenças incuráveis ou em estado vegetativo no processo de escolha dos limites do prolongamento da vida. Constatou-se que as regras jurídicas devem servir à sociedade de acordo com o contexto histórico, cultural e científico, seguindo o princípio da autonomia da vontade. Sendo assim, a necessidade de constantes debates com a sociedade permanece, visando a atualização do sistema jurídico brasileiro quanto à análise e aplicação adequada, no âmbito judicial ou legislativo, da eutanásia e do suicídio assistido.

Palavras-chave: Eutanásia; Suicídio assistido; dignidade da pessoa humana; autonomia da vontade; direito à vida.

\section{THE LIMITS BETWEEN THE DEFENSE OF THE RIGHT TO LIFE AND DEATH: A CURRENT ANALYSIS OF EUTANASIA IN BRAZIL.}

\begin{abstract}
:
This article aims to reflect the situation of terminally ill patients with incurable or vegetative conditions in the process of choosing the limits of the prolongation of life. It was found that legal rules should serve society according to the historical, cultural and scientific context, following the principle of autonomy of the will. Therefore, the need for constant debate with society remains, aiming at updating the Brazilian legal system regarding the analysis and adequate application, in the judicial or legislative scope, of euthanasia and assisted suicide.
\end{abstract}

Keywords: Euthanasia; Assisted suicide; dignity of human person; autonomy of the will; Right to life.

\section{INTRODUÇÃO}

A História relata que os costumes e atitudes diante da morte eram bem diferentes, em especial no oriente durante a idade média. Era normal que o homem soubesse quando a sua morte estava próxima. As doenças mais graves frequentemente eram mortais, dificilmente a morte era súbita, o que fazia que o doente presidisse a sua despedida, com direito a ritos,

\footnotetext{
* Mestre em Direito Público pela UNIFLU/FDC. Professora de Direito Social da Faculdade Municipal de LinharesES - FACELI, Professora de Direitos Humanos da IESFAVI/FACES. suelenagum@gmail.com

** Pós-Graduada em Gestão Estratégica em Recursos Humanos - FAESA - Faculdades Integradas EspíritoSantenses.Graduada em Administração pela UNESC - Centro Universitário do Espírito Santo e Graduanda em Direito da Faculdade do Espírito Santo - FACES. raquelfonseca23@hotmail.com
} 
proferir suas últimas palavras, conselhos e finalmente a sua despedida. Ao doente convinha morrer em um tempo adequado, para que desse tempo de realizar os ritos, e ao mesmo tempo, não se prolongasse em excesso as cenas das despedidas.

Em tempos atuais a morte é vergonhosa, não mais se reveste de um caráter de solenidade pública, pelo menos os momentos que a antecedem, pois não se deseja aceitar a morte, mas evitar que ela aconteça até o último momento e por vezes a qualquer custo. $\mathrm{O}$ doente, os familiares e todos que convivem com o doente são constantemente privados dos momentos que antecedem a morte, seja por uma parte dos familiares ou por profissionais da saúde, o que pode ser identificado o quanto ao longo dos anos o fim da vida foi transferido do ambiente doméstico para os ambientes hospitalares, com a clara intenção de afastar o doente dos demais entes queridos nos seus últimos momentos, alienando as partes envolvidas da situação e do processo decisório acerca da utilização ou limitação de tratamentos.

É sabido que o tempo de espera do fim altera-se, podendo ser prologando ou encurtado, a depender do tipo de tratamento a ser utilizado. Todavia diante do temor à morte e com os avanços tecnológicos e medicinais, os costumes contemporâneos tendem para a prática do excessivo prolongamento da vida.

No entanto, essa prática, excessiva ou não, de se dilatar a vida e afastar a morte não é unânime, e este artigo tem por objetivo refletir a situação de pacientes terminais, com doenças incuráveis ou em estado vegetativo no processo de escolha dos limites desse prolongamento da vida, considerando que por vezes ao promover a manutenção da vida há umaverdadeira extensão do sofrimento.

Para tanto, inicialmente será realizado um estudo sobre os aspectos históricos e conceituais da eutanásia e dos demais procedimento semelhantes e sua aplicabilidade no Brasil. Em seguida será abordado o conflito entre o princípio da dignidade da pessoa humana, fundamento da República Federativa do Brasil, e a Autonomia da Vontade. E por fim serão realizadas reflexões sobre os movimentos judiciais e legislativos em relaçãoà temática, bem como a necessidade de atualização do sistema jurídico-legislativo brasileiro em busca da resolução das demandas que crescem a cada dia.

\section{ASPECTOS HISTÓRICOS E CONCEITUAIS}


A vida e a morte são fenômenos, conceitos, antagônicos e ao mesmo tempo intrinsicamente relacionados. Discorrer sobre a vida e sobre a morte demanda reflexões profundas acerca da própria existência, balizada por padrões culturais tradicionais, sociais, legais, médicos e religiosos, geralmente definido primeiramente na história por argumentos filosóficos, ideológicos e religiosos, e posteriormente também com fundamentos científicos.

A vida é a continuidade de todas as funções de um organismo vivo (vegetal, animal e humano) ou, no mínimo, o período compreendido entre a concepção (ou a fecundação) e o evento morte, de conformidade com o pensamento de respeitável corrente científica das áreas da Saúde. (MARCHESINI JUNIOR, 2017)

Sobre a morte, Santos (2017) explica que sua primeira definição na História surge com Hipócrates, no século V a.c., em que a morte, segundo a sociedade grega, era determinada pela falência cardíaca. Já os povos judeus e cristãos, a morte se estabelece pelo pneuma, ou último suspiro. Somente no século XVII haverá uma primeira definição científica relacionada a um processo natural que culmina em cessação das funções vitais.

Ainda sobre os aspectos históricos é imperioso destacar que

\begin{abstract}
Nas primeiras comunidades humanas percebem-se conceituações seletivas mais utilitaristas, em que a ausência da medicina e a necessidade de labuta constante para sobrevivência forçavam a eliminação dos idosos, doentes e deficientes. Quanto aos povos celtas se via a obrigação dos filhos em dar morte boa a seus pais, assim também, na Idade Média, podem-se citar os golpes de misericórdia aos feridos nas batalhas. Já na América do Sul era constanteas eliminações dos deficientes feitas pelos povosindígenas.(BARBOSA, 2019)
\end{abstract}

Situação ainda encontrada no Brasil entre os silvícolas, sem contato com a sociedade, cujo costumes são protegidos pela legislação brasileira.

$\mathrm{Na}$ linha que torna os processos de vida e morte interligados e naturais, está a Eutanásia, que por sua vez, muito comumente, se torna pauta nas discussões públicas, principalmente quando algum caso de expressão internacional vem à tona, levantando novamente os questionamentos da sociedade quanto a legalidade desta prática.

Preliminarmente se faz indispensável a conceituação tanto de Eutanásia quanto das variáveis semelhantes, quais sejam o suicídio assistido e a ortotanásia.

A Eutanásia significa "boa morte" no sentido de amenizar dor e sofrimento.É o ato deliberado de provocar a morte sem sofrimento do paciente, é também chamada de eutanásia ativa pois exige a atuação comissiva de um terceiro - médico ou parente - que se utiliza de medicamentos ou outros meios para provocar a morte. 
A morte assistida ou suicídio assistido consiste no auxílio para a morte de uma pessoa, que pratica pessoalmente o ato que conduz à sua morte (ou suicídio), ou seja, a criação do risco é gerada pelo próprio paciente, e a ortotanásia, também chamada de eutanásia passiva, significa "morte no tempo certo" e caracteriza-se pela limitação ou suspensão do esforço terapêutico, ou seja, do tratamento ou dos procedimentos que estão prolongando a vida de doentes terminais, sem chance de cura, como por exemplo o desligamento de aparelhos, ou não reanimação de pacientes.

A prática da Eutanásia no mundo ainda representa um tabu para as sociedades, tocando em pilares culturais, religiosose éticos. Contudo, dadas as intensas transformações pelas quais a sociedade passou até os tempos atuais, com avanços tecnológicos e acesso a informação, novas discussões são abertas para a reavaliação de antigas práticas, como por exemplo a obrigatoriedade de permanência da vida acima de tudo.

$\mathrm{Na}$ atualidade, a eutanásia não se limita apenas aos casos dos doentes terminais, abrangendo também outras situações polêmicas, como as de recém-nascidos com anomalias congênitas (eutanásia precoce); pessoas que se encontram em estado vegetativo irreversível; pessoas inválidas sem a capacidade de cuidar de si mesmas. (MELO, 2017)

Segundo Milagrós Oliva (2017), dos mais de 190 países do mundo, apenas 6 autorizam alguma modalidade relacionada à Eutanásia, sendo eles, Estados Unidos desde 1997 (apenas alguns estados), Bélgica e Holanda desde 2002, Luxemburgo, a partir de 2008, Suíça desde 2015 e Canadá com a Lei aprovada em 2017. Dentre os países latino americanos a Colômbia permite o suicídio assistido, mas é preciso que o paciente seja portador de uma doença terminal, esteja em sofrimento e faça o pedido consciente.

$\mathrm{Na}$ legislação comparada, há duas possibilidades: a eutanásia direta, que consiste em provocar a morte do paciente, normalmente por meio de injeção de fármacos que lhe garantem uma morte doce; e a ajuda ao suicídio, que facilita os meios para que o próprio paciente coloque fim à vida. Neste caso, a ação costuma ser também através de um coquetel de medicamentos de ação rápida e indolor. (OLIVA, 2017)

Nocaminho inverso, enquanto a prática começa a ser vista como ato de piedade em outros países, no Brasil, a eutanásia, apesar de não ser citada, é até hoje enquadrada como homicídio no código penal vigente determinando pena para quem "matar, por piedade ou 
compaixão, paciente em estado terminal, imputável e maior, a seu pedido, para abreviar-lhe sofrimento físico insuportável em razão de doença grave” (ROSSI, 2017)

A esse respeito, mesmo sendo então um ato motivado por compaixão ao cessar o sofrimento ou sobrevida do doente até sua morte natural, a lei não compreende a eutanásia diferente do crime de homicídio, pois os parâmetros morais da sociedade que a redigiu focam no ato da interrupção da vida, desconsiderando a qualidade da mesma.

Na eutanásia, elimina o agente a vida da sua vítima com intuito e escopo de poupá-la de intenso sofrimento e acentuada agonia, abreviando-lhe a existência. Anima-o por via de consequência, o sentimento de comiseração e piedade. O Código penal brasileiro não aceita nem discrimina a eutanásia, mas não vai ao rigor de não lhe conceder o privilégio do relevante valor moral.

Comumente, as pessoas ao ouvirem falar em eutanásia logo a associam a doença e a enfermidade de desfecho fatal. No entanto, para os efeitos penais concernentes à concessão do privilégio, cumpre realçar-se que nem sempre há de estar a eutanásia indissoluvelmente vinculada a doença de desate letal. Por isso não se contenta a lei penal, nesse passo, com a simples ocorrência do relevante valor moral presente no episódio, exigindo que o crime seja cometido por relevante valor social ou moral. (PEDROSO, 2000,p.282 apud ROSA, 2017)

O Código Penal no art.122 dispõe também como crime quem induz, instiga e auxilia o suicídio, sendo então a morte assistida ou suicídio assistido análogo a essa disposição, contudo sem maiores aprofundamentos na questão da motivação, sendo desprezadas a dignidade e compaixão.

Se por um lado o Código Penal é,de certa forma, omisso quanto a eutanásia e ao suicídio assistido, uma proposta para a ética médica nesse sentido é oconceito ortotanásia, que representa uma espécie de "eutanásia passiva", ou "morte correta", expresso pela primeira vez na Resolução 1.895 de 2006 do Conselho Federal de Medicina no Diário Oficial da União, em que os médicos seriam autorizados a proceder em descontinuidade de tratamentos que prolonguem a vida de pacientes terminais ou doenças incuráveis, caso essa for sua vontade ou de seu representante legal, uma vez que representaria um catalisador do processo de morte.

Em outras palavras, a ortotanásia seria o auxílio médico para acelerar o óbito já naturalmente em processo, para assim aliviar o sofrimento do doente no prolongamento de sua vida de forma artificial (MELO, 2017). 
A Colombiana Adriana González Correa, em num evento promovido pelo Fórum Permanente de Biodireito, Bioética e Gerontologia e pelo Fórum Permanente de Direitos Humanos explicou sobre a legalização da eutanásia em 1997 no seu país, disse que:

(...) houve o entendimento que, no caso de doença incurável e terminal, acompanhada de grande sofrimento, solicitar o fim da vida era um ato de livre arbítrio, desde que a pessoa estivesse em pleno gozo de suas faculdades mentais.

Tão importante quanto viver dignamente é morrer dignamente, e o trabalho dos médicos envolvidos nesse processo é de respeito à dignidade humana, compaixão e misericórdia.

No entanto, até 2015, embora alguns médicos a praticassem, a falta de regulamentação sobre o tema criara um limbo jurídico. Somente nesse ano foram estabelecidas as diretrizes que normatizaram a liberação de um pedido de eutanásia. Foram criados comitês científico-interdisciplinares para avaliar as solicitações. Cada comitê tem um médico, para referendar a extensão e gravidade da doença; um psiquiatra ou psicólogo, para atestar a capacidade cognitiva do paciente; e um advogado para revisar se os procedimentos estão dentro dos termos legais. (TAVARES, 2018)

Situação semelhante à dos profissionais da saúde no Brasil, que possuem como único respaldo Resolução do Conselho Regional de Medicina e Portaria do Ministério da Saúde, porém não possuem a proteção legislativa dos seus atos e, tal como regularmente acontece nas situações de abordo, podem sofrer processos judiciais e prisões pelos atos cometidos. E nos casos relacionados àortotanásia a jurisprudência no Brasil ainda é incipiente.

A partir dos aspectos históricos e conceituais aqui apresentados passaremos a analisar os diversos argumentos que pairam sobre a possibilidade ou impossibilidade de aplicação da eutanásia e do suicídio assistido no Brasil, bem como das dificuldades para implementação efetiva da ortotanásia.

\section{A DIGNIDADE DA PESSOA HUMANA E OS LIMITES DE SUA APLICAÇÃO DIANTE DO CONFLITO COM O PRINCÍPIO DA AUTONOMIA DA VONTADE}

Refletir sobre a morte ou assuntos que lembre nossa finitude não é algo bem visto ou agradável, porém tem se tornado fundamental em nosso cotidiano. Vivemos mais e melhor, graças a evolução de várias ciências: medicina, farmacologia, tecnologia entre outras. Nossa visão de mundo e necessidades mudaram através dos tempos, assim como o conceito de dignidade da pessoa humana.

De acordo com Sidney Guerra (2013, p.53) "A dignidade da pessoa humana encontra alicerces no pensamento cristão, segundo o qual, criada à imagem e semelhança de Deus, a 
pessoa é dotada de atributos próprios e intrínsecos, que a tornam especial e detentora de dignidade" e Sarlet(2001, p. 60) afirma que

Temos por dignidade da pessoa humana a qualidade intrínseca e distintiva de cada ser humano que o faz merecedor do mesmo respeito e consideração por parte do Estado e da comunidade, implicando, neste sentido, um complexo de direitos e deveres fundamentais que assegurem a pessoa tanto contra todo e qualquer ato de cunho degradante e desumano, como venham a the garantir as condições existenciais mínimas para uma vida saudável, além de propiciar e promover sua participação ativa corresponsável nos destinos da própria existência e da vida em comunhão dos demais seres humanos.

Indubitavelmente a Dignidade tem como marco conceitual de nosso tempo, a Declaração Universal de Direitos Humanosde 1948 ao estabelecer em seu preâmbulo que

(...) o reconhecimento da dignidade inerente a todos os membros da família humana e de seus direitos iguais e inalienáveis é o fundamento da liberdade, da justiça e da paz no mundo. (...) Considerando que os povos das Nações Unidas reafirmaram, na Carta, sua fé nos direitos fundamentais do homem, na dignidade e no valor da pessoa humana e na igualdade de direitos do homem e da mulher, e que decidiram promover o progresso social e melhores condições de vida em uma liberdade mais ampla. (ONU, 2009, p. 1)

Encontra-se neste documento os fundamentos dos direitos de todos os seres humanos, inclusive a dignidade à vida, liberdade, igualdade e tantas outras condições indispensáveis e necessárias para uma vida plena. Entretanto, há também em seuartigo que "Ninguém será submetido à tortura nem a tratamento ou castigo cruel, desumano ou degradante. "(ONU, 2009, p. 4). Posição reafirmada pela Constituição Federal de 1988.

Inscrita no rol dos princípios fundamentais de nossa Constituição, a Dignidade da Pessoa Humana, promove hodiernamente a reflexão acerca das práticas que promovem o alívio de pessoas hospitalizadas em estados irreversíveis, e que muitas vezes optam elas mesmas por esses recursos.

Neste sentido Alexandre de Moraes (2011, p.61)destaca que a dignidade da pessoa humana é um valor espiritual e moral inerente à pessoa, que se manifesta singularmente na autodeterminação consciente e responsável da própria vida de modo que possam ser feitas limitações ao exercício dos direitos fundamentais. Essa autodeterminação consciente está fundada no princípio da autonomia da vontade presente no ordenamento jurídico Brasileiro.

Sob o ponto de vista do Senador Lasier Martins do PSD/RS, autor do projeto de lei (PL 7/2018) pela regularização da Eutanásia no Brasil, que será analisado a seguir, "o respeito à manifestação do paciente consagra o princípio da autonomia da vontade, inclusive nessa delicada fase da vida, consagrando a liberdade individual e aperfeiçoando nosso modelo de 
assistência à saúde" (SENADO, 2018), ou seja goza de proteçãoa escolha da morte, portanto, uma vontade sobre a qual não cabe interpretação (MELO, 2017).

Diante dos princípios acima explanados repousa o debate. De um lado, os defensores da livre escolha e da morte com dignidade. De outro, religiosos e os adeptos da vida como um dever, e não uma vontade (PINHEIRO, 2017). No mesmo sentido

\begin{abstract}
Para Fermin Roland Schramm, pesquisador da Fiocruz (...) há duas abordagens divergentes em relação ao tema: 'a bioética religiosa se baseia no princípio da sacralidade da vida e não admite exceções. Já a bioética laica prioriza a qualidade da existência, a diminuição do sofrimento evitável e se fundamenta no respeito à liberdade individual'. Na sua opinião, a sociedade tem verdadeiro horror à morte e rechaça sua ideia: 'há um desejo legítimo de lutar contra o sofrimento e a morte, mas há um limite até onde isso é possível. Depois, temos a obstinação terapêutica, que pode se transformar em autêntica tortura, não levando em conta a qualidade de vida'. (TAVARES, 2018.)
\end{abstract}

A morte voluntária ou morte assistida são opções que ainda encontram grande resistência na aceitação, sobretudo de sociedades em que a lei é construída sobre alicerces religiosos. O Brasil é um dos países mais religiosos do mundo, com $79 \%$ da população autodeclarada crente em alguma fé (BBC, 2017).

Nesse viés, mesmo o Estado sendo laico, as pessoas que o conduzem não são máquinas dissociadas de suas convicções, refletindo assim seu posicionamento pessoal mesmo em questões públicas.

Há de se ressaltar que as leis vigentes que condenam tais práticas foram compostas em outro momento sócio histórico, ou seja, para outro perfil de sociedade, uma vez que a cada geração há mudanças de posturas, necessidades, opiniões e crenças.

Deve-se lembrar, ainda, que por mais que as pessoas ainda estejam ligadas às convicções tradicionais, ideológicos e/ou religiosas, que porventura venham a condenar qualquer forma de interrupção da vida, a legalização de práticas polêmicas como eutanásia, suicídio assistido ou ortotanásia são questões de ordem pública, que devem ser pensadas e garantidas tendo em vista o bem comum, e devem ser conduzidas de forma impessoal.

Apesar de antigo, manter o debate sobre a permissão legal da Eutanásia é contribuir para a consolidação de uma compreensão jurídica sobre o tema, qual seja,o respeito a manutenção de uma vida digna também através dos desígnios da liberdade e autonomia dos cidadãos componentes de uma sociedade regulada pelo Estado Democrático de Direito.

Ora, se vida e morte são intrinsicamente ligadas, se lhe é garantido a vida e estar com dignidade, porque não prever também que a morte possa ser de livre iniciativa caso cumpra 
também com os desígnios da dignidade? Caso contrário poderá viabilizar processos de verdadeira tortura.

Ou seja, a discussão sobre Eutanásia perpassa os domínios da Sociedade, da Ciência e do Direito, tramitando entre o choque de argumentos de diferentes naturezas e interesses, pois garantir a vida a qualquer custo é ferir a dignidade da pessoa humana em determinados casos, bem como sua liberdade de escolha e autonomia sobre sua própria vida, e porque não sua morte?

Santos (2017) propõe estar fora da alçada da lei definir quando ocorre o fenômeno da morte, cabendo aos campos da medicina e da ciência. Nesta seara o Direito só pode intervir para exigir a segurança quanto à realização do ato em determinados estabelecimentos, porém, a última palavra caberá à Medicina. [...] O conceito médico-forense de morte é um conceito dinâmico, aberto e funcional; (...) (SANTOS, 2017, p.376).

Neste sentido, Maria Helena Diniz (2006, p. 16) argumenta que

O princípio da Autonomia da Vontade requer que o profissional da saúde respeite a vontade do paciente, ou de seu representante, levando em conta, em certa medida, seus valores morais e crenças religiosas. Reconhece o domínio do paciente sobre a própria vida (corpo e mente) e o respeito a sua intimidade, restringindo, com isso, a introdução alheia no mundo daquele que está sendo submetido a um tratamento.

Destaca-se ainda que a autonomia da vontade tem sua essência na liberdade que o ser humano tem em tomar decisões a partir de suas convicções. Dentro desta concepção, o indivíduo é autor de uma "lei", a qual terá que seguir. Cumprir sua própria "lei" é sinal de maturidade daquele que vê na sua liberdade de decidir a concretização de uma vontade personalíssima e intransferível.

Nessa perspectiva, escreveu José Afonso da Silva(2000, p. 109):

Dignidade da Pessoa Humana, é um valor supremo que atraí o conteúdo de todos os direitos fundamentais do homem, desde o direito à vida, concebido como referência constitucional unificadora a todos os direitos fundamentais [observam Gomes Canotilho e Vital Moreira], o conceito de dignidade da pessoa humana obriga a uma densificação valorativa que tenha em conta o seu amplo sentido normativoconstitucional e não uma qualquer ideia apriorística do homem, não podendo reduzir-se o sentido da Dignidade Humana à defesa dos direitos pessoais tradicionais, esquecendo-a nos casos dos direitos sociais, ou invocá-la para construir a teoria do núcleo da personalidade individual, ignorando-a quando se trate de garantir as bases da existência humana. Daí decorre que a ordem econômica há de ter por fim assegurar a todos existência digna (art. 270), a ordem social visará a realização da justiça social (art. 193), a educação, o desenvolvimento da pessoa e seu preparo para o exercício da cidadania (art. 205) etc, não como meros enunciados formais, mas como indicadores do conteúdo normativo eficaz da dignidade da pessoa humana. 
Desta forma, ressaltamos que não existe um direito absoluto, é perfeitamente cabível ao ser humano a possibilidade de definir sobre o direito de morrer, a julgar por, não ter sido dada a este, a oportunidade de viver de forma digna.

Diante dos apontamentos apresentados é possível afirmar que prolongar a morte é submeter o ser humano a um sofrimento desumano, e assim como na Declaração Universal dos Direitos Humanos a Carta Constitucional de 1988 descreve que “[...] ninguém será submetido à tortura nem a tratamento desumano e degradante". Assim permitir que a ciência faça daquele que já não tem mais saúde uma cobaia de tratamentos intermináveis e dolorosos, e sem certeza de reversão do quadro clínico é infringir o preceito constitucional.

Os argumentos acima expostos demonstram o quanto a legislação brasileira, ao vedar a implementação da eutanásia e do suicídio assistido, confronta claramente com o ordenamento jurídico pátrio, em especial quanto à observância dos princípios da Dignidade da Pessoa Humana e da Autonomia da Vontade.

Por outro lado, o Código de Ética Médico, o Conselho Regional de Medicina, através de resoluções, e o Ministério da Saúde, através de portarias, tem construído instrumentos que viabilizem aos profissionais da saúde a tomada de atitudes que caracterizam a ortotanásia.

Em resumo a Resolução 1.805/2006 permite ao médico limitar ou suspender procedimentos e tratamentos que prolonguem a vida do doente em fase terminal, de enfermidade grave e incurável, respeitada a vontade da pessoa ou de seu representante legal; e a Resolução 1.995/2012 dispõe sobre as diretivas antecipadas de vontade dos pacientes, tais disposições proporcionam evitar ou diminuir o estágios de dor do paciente, proporcionando assim a aceitação do processo de morte de forma menos agressiva, sem submeter o paciente a procedimento invasivos que não podem mais proporcionar seu restabelecimento pleno.

Neste sentido o Código de Ética Médica autoriza a prática da ortotanásia, que consiste em aliviar o sofrimento de um doente terminal através da suspensão de tratamentos que prolongam a vida, mas não curam nem melhoram a enfermidade. Além de recomendar ao médico que deixe de empreender essas ações, o código determina que esses profissionais levem em consideração a vontade expressa do paciente ou do seu representante legal.

Diante do exposto, veremos a seguir que o Brasil caminha a passos largos para a consolidação jurisprudencial e legislativa para o reconhecimento da ortotanásia no Brasil. Porém não encontramos qualquer avanço quanto à Eutanásia e ao Suicídio assistido, o que 
demonstra claramente a necessidade de permanência da discussão sobre o tema, em especial em ambientes acadêmicos, visando o subsidiar futuros posicionamentos legislativos e jurisprudenciais sobre o tema.

\section{JUDICIALIZAÇÃO E PROPOSTAS LEGILATIVAS DO SENADO FEDERAL SOBRE} A APLICABILIDADE DA ORTOTANÁSIA

Em 2015 foi divulgadopelo site de notícias do Jornal Estadãoa ação judicial julgada em 2013 em que uma advogada conquistou a primeira autorização judicial para aplicação da ortotanásia no Brasil. "Em decisão inédita, a Justiça brasileira autorizou uma advogada a ter "morte digna", o que, nesse caso, significa não ter de passar por tratamento desnecessário caso desenvolva, no futuro, doença irreversível que comprometa a capacidade física e a consciência." (CAMBRICOLI, 2015).

De acordo com a notícia a ação judicial foi movida pela advogada Rosana Chiavassa, de 54 anos, e avaliada pelo juiz Alexandre Coelho, na época titular da 2. ${ }^{a}$ Vara Cível do Fórum João Mendes, em São Paulo e a sentença foi dada em junho de 2013, mas somente agora a autora quis divulgar o caso.

É um caso claro e evidente de manifestação da vontade prévia de não prolongar a vida em casos irreversíveis. Na prática isso já ocorre através dos testamentos vitais, documento registrado em cartório em que se pode deixar claro por quais tipos de procedimentos o paciente aceita passar. No entanto, a vontade do paciente posta em testamento pode ser sobrepujada pela vontade de familiares ou responsáveis legais.

Diante de inúmeros casos práticos vividos pela autora da ação no exercício da advocacia, ela buscou a chancela da Justiça. Rosana explicou que

O testamento vital pode ser questionado pela família. Podem alegar que a pessoa
tenha registrado o documento já em um momento de insanidade ou em um surto de
desespero pela descoberta de uma doença, por exemplo. Quis entrar na Justiça para
provar que estou completamente saudável e tenho consciência da minha
decisão.(CAMBRICOLI, 2015)

Importante destacar que na decisão o juiz afasta qualquer ideia de eutanásia, proibida no Brasil, uma vez que a autora não pretende a morte obtida mediante intervenção humana, mas sim a vida, com toda a sua dignidade, evitando-se apenas a positivação de procedimentos médico-hospitalares que sabidamente nenhum resultado obterão quanto à recuperação da saúde e reversão do quadro mórbido. 
Com a finalidade de garantir que sua vontade seja respeitada, a autora da ação elencou seis médicos que a acompanham e deverão ser consultados para que se determine se o quadro é irreversível e quais procedimentos podem ser dispensados.

Por se tratar de caso inédito no Brasil, sem precedentes jurídicos não há possibilidade de obter a absoluta certeza de que, caso desenvolva uma doença irreversível, sua vontade seja respeitada, mas indiscutivelmente é um dos caminhos pelo qual o Brasil pode iniciar um novo comportamento social e até mesmo judicial sobre casos de ortotanásia.

Em contrapartida, diferentemente da ortotanásia que não há permissão ou proibição legal, ficando a critério da interpretação jurisdicional, como já explanado anteriormente, a eutanásia no brasil é equiparada a homicídio, e o suicídio assistido é equivalente ao ato de instigar ao suicídio, ambos, portanto, crimes tipificados no código penal brasileiro.

Visando colocar o Brasil em consonância com a tendência mundial de garantir, por meio de lei, a possibilidade de o paciente manifestar e ter respeitada a sua vontade, e considerando o respeito à dignidade e à autonomia do paciente, pela sua qualidade de vida e pela humanização da morte há dois projetos de lei em trâmite no Congresso Nacional, visando a adequação do Código Penal brasileiro.

Um diz respeito ao Projeto de Lei do Senado ${ }^{\circ} 149$, de 2018, de autoria do Senador Lasier Martins (PSD/RS), que dispõe sobre as diretivas antecipadas de vontade sobre tratamentos de saúde e estabelece a possibilidade de toda pessoa maior e capaz declarar, antecipadamente, o seu interesse de se submeter ou não a tratamentos de saúde futuros, caso se encontre em fase terminal ou acometido de doença grave ou incurável. A situação atual do procedimento legislativo é "aguardando designação do relator da Comissão de Assuntos Sociais", conforme informações do site do Senado (SENADO, PL nº 7/2018).

O outro Projeto de Lei do Senado $n^{\circ} 7$, de 2018, de autoria do Senador Pedro Chaves (PSC/MT), está mais avançado na tramitação edispõe sobre os direitos dos pacientes em serviços de saúde; altera o Decreto-Lei n 2.848, de 7 de dezembro de 1940 (Código Penal), para isentar do crime de omissão penalmente relevante a falta de instituição de suporte de vida ou a não realização de tratamento ou procedimento médico recusados; e altera a Lei $\mathrm{n}^{\circ}$ 6.437, de 20 de agosto de 1977, que configura infrações à legislação sanitária federal, estabelece as sanções respectivas, e dá outras providências, para proibir a reutilização de produtos para a 
saúde descartáveis. A situação atual do procedimento legislativo é que foi concedido pedido de vista em 20/03/2019 pela a Comissão de Constituição, Justiça e Cidadania.

De acordo com o Parecer da Comissão de Constituição, Justiça e Cidadania, em decisão terminativa, sobre o Projeto de Lei do Senado no 7 de 2018, do Senador Pedro Chave disponível

\begin{abstract}
A alteração do Código Penal é importante para resguardar o profissional de saúde contra punições por omissão em casos de recusa de tratamento pelo paciente. O respeito à manifestação do paciente consagra o princípio da autonomia da vontade, inclusive nessa delicada fase da vida, consagrando a liberdade individual e aperfeiçoando nosso modelo de assistência à saúde.

(...)

Propomos, entretanto, que não será aceita a manifestação de recusa nas seguintes situações: i) quando houver risco para a saúde pública, nos casos de recusa de tratamento ou procedimento essencial para o controle de doenças ou agravos coletivos à saúde; e ii) quando a manifestação feita pelo representante recusar tratamento ou procedimento capaz de salvar a vida do paciente que esteja civilmente incapaz e sob risco iminente de morte.
\end{abstract}

Tanto os projetos legislativos como a ação judicial aqui são utilizados como parâmetros para justificar que "é em face da equiparação do direito à vida aos demais direitos fundamentais que não cabe ao Estado impedir ao indivíduo a liberdade de renunciar ao viver quando tal condição lhe implica degradação física ou psicológica.” (BARBOSA, 2019)

Ampliando o olhar para futuros comportamentos sociais, jurídicos e legislativos Barbosa (2019)se utiliza dos argumentos jurisprudenciais do casoreferente ao aborto de anencéfalos analisado pelo STF na Ação Direta de Inconstitucionalidade $n^{\circ} 3510$. Segundo a autora:

Nesse sentido, percebendo-se a interpretação dada pelo Supremo Tribunal Federal
ao direito fundamental à vida quando do julgamento da ADI 3.510 , passa-se a
compreender a mesma não apenas enquanto um direito a permanecer vivo, como
também, baseado pela fraternidade, um direito a viver de modo adequado, sendo o
mesmo equiparado a todos os demais direitos fundamentais positivados na CF- 88 e,
portanto, passível de renunciabilidade diante do caráter de controle de
constitucionalidade presente no princípio da interpretação conforme, se vê a
inconstitucionalidade em tratar de modo igualitário o homicídio privilegiado, como
vem acontecendo na prática judiciária brasileira, e a conduta eutanásica.

Ou seja, de acordo com o posicionamento acima transcrito, os fundamentos utilizados no julgamento da ADI 3510, podem viabilizar futuros projetos que permitirão noordenamento brasileiro,quiçá,não mais tratar a eutanásia e o suicídio assistido como homicídio ou instigação ao suicídio.

Sendo assim, o posicionamento adotado pela Corte Constitucional na referida Ação Direta de Inconstitucionalidade, sem dúvida, é um fator preponderante que poderá ser um 
facilitador das discussões sobre o reconhecimento da eutanásia e do suicídio assistido no Brasil, considerando que, diferentemente do feto, o doente que ainda possuicapacidade de manifestação de vontade, deve ser ouvido e atendido em observância aos princípios da dignidade da pessoa humana e da autonomia da vontade.

\section{CONCLUSÃO}

Os projetos de lei e o caso judicial acima apresentado demonstram claramente a evolução da aplicação da ortotanásia no Brasil, além de abrir caminhos para futuras discussões mais aprofundadas sobre o tema.

Quanto ao debate sobre a Eutanásia e Suicídio assistido, sugere-se que sejam reconsiderados e reavaliados antigos valores morais, que por sua vez possam não mais atender às demandas sociais da atualidade, bem como considerar o parecer médico/científico da dignidade em situação terminal e sobrevida, além da funcionalidade e liberdade da opção pela morte, para que assim não seja ela limitada a uma visão sob o prisma da perversidade e condenação moral, mas pelo alívio da dor, sofrimento e como um ato final de caridade a quem não possui outras opções de sobrevivência com dignidade.

Cabe ressaltar que a Constituição assegura o direito à vida, mas não necessariamente o dever a ela a qualquer custo. Qual o limite em manter viva uma pessoa que não tem mais capacidade de viver dignamente? Somente para atender a função social e o princípio da inviolabilidade da vida? Constata-se que assim haverá a inobservância tanto do princípio da dignidade da pessoa humana, como também, o princípio da autonomia da vontade, algo que deve ser respeitado frente ao pedido do enfermo sem perspectiva de melhora.

Afinal o Estado existe em função dos indivíduos que dele o compõem e não o contrário, e as regras jurídicas devem servir à sociedade de acordo com o contexto histórico, cultural e científico, por isso, enquanto a eutanásia e o suicídio assistido não for analisado adequadamente seja no âmbito judicial, seja no âmbito legislativo, haverá a necessidade de debates com a sociedade, principalmente para casos excepcionais, assim como houve, por exemplo, recentemente para o aborto, e no passado para o estado de necessidade, a legitima defesa e a pena de morte em tempo de guerra.

Assegurar a vida a qualquer custo, sem o devido respeito ao que é considerado “digno" é desrespeitar e sentenciar o ser humano. Prolongar a vida em casos especialíssimo, 
como em doentes terminais pode até ser considerado tortura, pois através do flagrante desrespeito à autonomia da vontade e à liberdade, permite-se a manutenção do sofrimento frente a uma situação irreversível.

A lei que trata a vida como bem indisponível é a mesma que tem como princípio o direito à liberdade. Ser livre é ter autonomia para decidir o seu destino.

\section{REFERÊNCIAS}

BARbosA, G. S. S., LOSURDO, F. Eutanásia no Brasil: entre o Código Penal e a dignidade da pessoa humana. Revista de Investigações Constitucionais, Curitiba, vol. 5, n. 2, p. 165-186, maio/ago. 2018. Acesso em 30 de mar. 2019. Disponível em file:///C:/Users/Lap\%20Acer/Downloads/52151-239813-1-PB.pdf

BARROSO, L. R. A dignidade da pessoa humana no direito constitucional contemporâneo: Natureza jurídica, conteúdos mínimos e critérios de aplicação (Versão provisória para debate público). Disponível em: 〈http://www.luisrobertobarroso.com.br/wpcontent/themes/LRB/pdf/a_dignidade_da_pessoa_humana_no_direito_constitucional.pdf $>$ Ac esso em: 07 abr. 2017

BBC. Os países mais e menos religiosos do planeta. Disponível em: http://www.bbc.com/portuguese/noticias/2015/04/150414_religiao_gallup_cc. Acesso em: 08 abr. 2017.

BRASIL. Constituição da República Federativa do Brasil de 1988. Disponível em: $<$ http://www.planalto.gov.br/ccivil_03/constituicao/constituicao.htm>. Acesso em: 07 abr. $2017 \mathrm{a}$.

BRASIL. Decreto-Lei n.2.848, de 7 de dezembro de 1940. Disponível em:>http://www.planalto.gov.br/ccivil_03/decreto-lei/Del2848compilado.htm<. Acesso em 07 abr. $2017 \mathrm{~b}$.

CAMBRICOLI, F. Justiça autoriza advogada a ter 'morte digna'. Jornal O Estado de São Paulo, Saúde, atualizado em 24 de janeiro de 2015, 23h39, São Paulo, 2015. Acesso em 31 de mar de 2019. Disponível em https://saude.estadao.com.br/noticias/geral,justica-autorizaadvogada-a-ter-morte-digna, 1624407

DINIZ, M. H.Curso de Direito Civil Brasileiro. V.1 São Paulo: Saraiva, 2006.

GUERRA, S. Direitos humanos: curso elementar. São Paulo: Saraiva, 2013.

KUMAGAI, C.; MARTA, T. N. Princípio da dignidade da pessoa humana. Acesso em: 07 abr. 2017.Disponível em: <http://www.ambitojuridico.com.br/site/index.php?n_link=revista_artigos_leitura\&artigo_id=7830> 
MARCHESINI JUNIOR, W.Biodireito: reflexões sobre o direito de nascer e de morrer. Acesso em: 08 abr. 2017.Disponível em:>http://www.tribunapr.com.br/noticias/biodireitoreflexoes-sobre-o-direito-de-nascer-e-de-morrer/<.

MELO, A. C. P. A polêmica da legalização da eutanásia no Brasil: o dever ético de respeito às vontades antecipadas dos pacientes terminais. Disponível em: $<$ https://jus.com.br/artigos/42873/a-polemica-da-legalizacao-da-eutanasia-no-brasil-o-deveretico-de-respeito-as-vontades-antecipadas-dos-pacientes-terminais/1> Acesso em: 07 abr. 2017.

MÖLLER, L. L. Direito à morte com dignidade e autonomia - $O$ direito à morte de pacientes terminais e os princípios da dignidade e autonomia da vontade. Curitiba: Juruá, 2007.Acesso em: 08 abr. 2017. Disponível em: $<$ https://books.google.com.br/books?id=xSTE2ioJU5EC\&pg=PA27\&dq=ANTIGONA+E + A + DIGNIDADE\&hl=pt-

BR\&sa $=$ X\&ved=0ahUKEwj8q52m1ZXTAhVDIJAKHTm1AA0Q6AEIMDAC\#v=onepage \& $\mathrm{q}=\mathrm{ANTIGONA} \% 20 \mathrm{E} \% 20 \mathrm{~A} \% 20 \mathrm{DIGNIDADE} \& \mathrm{f}=$ false $>$.

MORAES, A. de. Constituição do Brasil Interpretada e Legislação Constitucional. 8. ed. São Paulo: Atlas, 2011.

MOTTA, A. F. M. R. A dignidade da pessoa humana e sua definição.Acesso em: 07 abr. 2017.Disponível em: <http://www.ambitojuridico.com.br/site/?n_link=revista_artigos_leitura\&artigo_id=14054>.

OLIVA, M.P. Quem decide como devemos morrer?Acesso em: 7 abr. 2017.Disponível em:> http://brasil.elpais.com/brasil/2017/03/31/ciencia/1490960180 147265.html<.

OLIVEIRA, E. G. Eutanásia: conflito de garantias fundamentais? Acesso em: 09 abr. 2017. Disponível em: <http://www.ambitojuridico.com.br/site/index.php?n_link=revista_artigos_leitura\&artigo_id=5225>

ONU. Declaração Universal dos Direitos Humanos. Acesso em: 08 abr. 2017.Disponível em: <http://www.onu.org.br/img/2014/09/DUDH.pdf>

PINHEIRO, A. Fardo da vida. Inglaterra discute o direito e o dever de viver. Acesso em: 07 abr. 2017.Disponível em: <http://www.conjur.com.br/2010-jul-22/inglaterra-volta-discutirlimites-entre-direito-dever-viver $>$.

ROSA, I.P.C. A Eutanásia no Direito Brasileiro. Acesso em: 07 abr. 2017.Disponível em:> http://www.egov.ufsc.br/portal/conteudo/eutan\%C3\%A1sia-no-direito-brasileiro-0<.

ROSSI, M. Eutanásia pode virar crime no Brasil, com pena de quarto anos de prisão.Acesso em: $\quad 07 \quad$ abr. 2017.20 Disponível em:> http://brasil.elpais.com/brasil/2015/05/07/politica/1431030917_335982.html<. 
SANTOS, M.C.C.L dos. Conceito medico-forense de morte.Acesso em: 08 abr. 2017.Disponível em:>http://www.revistas.usp.br/rfdusp/article/viewFile/67369/69979<.

SANTOS, R. S.; DUARTE, H. G. Eutanásia: o direito de morrer à luz do princípio constitucional da dignidade da pessoa humana.Acesso em: 09 abr. 2017.Disponível em: $<$ http://www.ambito-

juridico.com.br/site/?n link=revista artigos leitura\&artigo $\mathrm{id}=17150 \&$ revista caderno=27>

SARLET, Ingo Wolfgang. Dignidade da pessoa humana e direitos fundamentais. Porto Alegre: Livraria do Advogado, 2001.

SILVA, José Afonso. Curso de Direito Constitucional.Ed. Malheiros, São Paulo: 2000.

SENADO. Notícias. Pacientes terminais poderão recusar procedimentos de suporte de vida. Atualizado em 02/08/2018, 09h39, Brasília, 2018. Acesso em 30 de mar. 2019. Disponível em https://www12.senado.leg.br/noticias/materias/2018/07/26/pacientes-terminais-poderaorecusar-procedimentos-de-suporte-de-vida

SENADO. Projeto de Lei $\mathrm{n}^{\circ} 7$ de 2018. Acesso em 30 de mar de 2019. Disponível em https://www25.senado.leg.br/web/atividade/materias/-/materia/132125

SENADO. Projeto de Lei $\mathrm{n}^{\circ} 149$ de 2018. Acesso em 30 de mar de 2019. Disponível em https://www25.senado.leg.br/web/atividade/materias/-/materia/132773

TAVARES, M. Precisamos falar sobre eutanásia. O Globo. Caderno de saúde. Rio de Janeiro, 2018. Acesso em 30 de mar. 2019. Disponível em https://g1.globo.com/bemestar/blog/longevidade-modo-de-usar/post/2018/09/11/precisamosfalar-sobre-eutanasia.ghtml

VIANA, M. Z. V.; DUARTE, H. G. A dignidade da pessoa humana enquanto valor supremo da ordem jurídica. Acesso em: 09 abr. 2017.Disponível em: <http://www.ambitojuridico.com.br/site/index.php/abrebanner.php?n link=revista artigos leitura\&artigo id=183 97\&revista_caderno=9> 